\title{
TICKS AND ASSOCIATED TICK-BORNE PATHOGENS FROM DOGS AND RED FOXES FROM BULGARIA
}

\author{
M. S. PANAYOTOVA-PENCHEVA ${ }^{1}$, B. VICHOVA ${ }^{2}$, \\ V. I. DAKOVA ${ }^{1} \&$ D. S. SALKOVA ${ }^{1}$ \\ ${ }^{1}$ Institute of Experimental Morphology, Pathology and Anthropology with \\ Museum, Bulgarian Academy of Sciences, Sofia, Bulgaria; ${ }^{2}$ Institute of \\ Parasitology, Slovak Academy of Sciences, Košice, Slovakia
}

\section{Summary}

Panayotova-Pencheva, M. S., B. Vichova, V. I. Dakova \& D. S. Salkova, 2021. Ticks and associated tick-borne pathogens from dogs and red foxes from Bulgaria. Bulg. J. Vet. Med., 24, No 4, 608-613.

Climate changes in recent years led to a sharp rise in the tick population and an increase in the number of animals and people with tick-borne infections. The domestic and wild carnivores, especially the dogs, have a huge role for the distribution of ticks in certain areas. In this study 60 ixodid ticks collected from domestic dogs and red foxes from Bulgaria have been investigated for infection with Ehrlichia canis, Hepatozoon canis, Babesia spp., and Rickettsia spp. The results showed that the dogs were infected with two tick species - Rhipicephalus sanguineus (72\%) and Ixodes ricinus $(28 \%)$. The red foxes were infected with only one species - I. ricinus. Out of all R. sanguineus ticks, $43.6 \%$ were female and $56.4 \%$ male. The opposite was observed for I. ricinus - female specimens $(86.7 \%)$ were significantly more prevalent than males $(13.3 \%)$. Similar trend was found out for $I$. ricinus collected from red foxes $-66.7 \%$ of the ticks were female and $33.3 \%$ male. Infectious agents were found in $31.7 \%$ of the investigated ticks. Ehrlichia spp. was established in $79 \%$ and Rickettsia spp. in $21 \%$ of the infected ticks. Ehrlichia spp. was found only in ticks collected from dogs. The majority of the ticks infected with Ehrlichia spp. were Rh. sanguineus $(93.3 \%)$ and only one tick was I. ricinus (6.7\%). Four ticks were positive for Rickettsia spp., two were Rh. sanguineus and two - I. ricinus, one of the latter was found on a fox. This is the first report about detection of Ehrlichia spp. in Rh. sanguineus ticks from Bulgaria as well as Rickettsia spp. in I. ricinus ticks collected from red foxes from this country.

Key words: Bulgaria, dog, Ehrlichia canis, Ixodes ricinus, red fox, Rhipicephalus sanguineus, Rickettsia spp.

Currently, multiple anthropogenic stressors including climate change, habitat loss and fragmentation, urbanisation, agricultural expansion and intensification, to- 
gether with other changes in the use of water and land resources, are directly or indirectly impacting all species on earth. Such processes have also significant effects on host-parasite interactions and infectious disease risks. Due to global changes (climate, economic and social) in the last decades, emergence of new serious infectious diseases of different aetiology as well as spreading of already known diseases can be seen.

Ixodid ticks are involved in the emergence and circulation of dangerous diseases of different nature, including such with a zoonotic character. They have been described as vectors of human diseases with bacterial origin as spotted fever rickettsioses, recurrent fever borrelioses, tularemia, and Q fever (Parola \& Raoult, 2001). A number of Gram-negative bacteria have been identified in ticks, including Chromobacterium violaceum, Pasteurella haemolytica, Pseudomonas aeruginosa, and Serratia marcescens potentially pathogenic for man or animals (Stojek \& Dutkiewicz, 2004). Tick-borne encephalitis is considered the most important tickborne viral disease of humans in Eurasia (Pfeffer \& Dobler, 2011). Ixodid ticks are also vectors for parasitic pathogens like Babesia and Theileria, in many cases they appear to be the leading factors in the development and distribution of these infections (Perez de Leon et al., 2013).

This work presents the results from investigation of species composition of ixodid ticks and associated pathogens circulating among domestic dogs and red foxes from two regions of Western Bulgaria.

Sixty ixodid ticks were examined, 54 of them were from domestic dogs and 6 from red foxes. The ticks were collected in 2018 during checkup of house dogs in veterinary practices in Sofia and necrop- sies of two red foxes found dead on roadways in Blagoevgrad district. The identification of the found ticks was performed according to guides by Estrada-Pena et al. (2004) and Georgieva \& Gecheva (2013). The ticks were investigated for the following pathogens: protozoans from genus Babesia and the species Hepatozoon canis and bacteria from genus Rickettsia and the species Ehrlichia canis.

The genomic DNA was extracted with NucleoSpin ${ }^{\circledR}$ Tissue kit (MACHEREYNAGEL, Germany) according to the producer's manual. To detect babesiae, the genus-specific $18 S \mathrm{rDNA}$ gene was amplified following the methodology and using the primers described by Casati et al. (2006). For $H$. canis a portion of $18 \mathrm{~S}$ $r R N A$ gene was amplified, using primers HepF (CTTATTATTCCATGCTGCAG) and HepR (ATACATGAGCAAAATCT CAAC) as described by Inokuma et al. (2002). To detect rickettsiae, a part of the genus-specific gene D was amplified using primers D767f (CGATGGTAG CATTAAAAGCT) and D1390r (CTT GCTTTTCAGCAATATCAC) (Sekeyová et al., 2001). For Ehrlichia canis a region of $16 \mathrm{~S} r R N A$ gene using the pair of primers EHR 521 (TGTAGGCGGTT CGGTAAGTTAAAG) and EHR 747 (GCACTCATCGTTTACAGCGTG) was amplified as described by Pancholi et al. (1995). For electrophoresis of the PCR products obtained, $1.5 \%$ agarose and TAE buffer were used.

Thirty-nine of the ticks collected from dogs were of the species Rhipicephalus sanguineus (17 female and 22 male) and 15 were identified as Ixodes ricinus (13 female and 2 male). Ticks from foxes were only I. ricinus (4 females and 2 males).

The PCR results are summarised in Table 1 . They show that $72 \%$ of the ticks 
Ticks and associated tick-borne pathogens from dogs and red foxes from Bulgaria

Table 1. Investigations of ixodid ticks collected from carnivores from Bulgaria for pathogens

\begin{tabular}{|c|c|c|c|c|c|c|}
\hline \multirow[t]{2}{*}{ Animals } & \multirow[t]{2}{*}{ Tick species } & \multirow{2}{*}{$\begin{array}{l}\text { Sex and } \\
\text { number of } \\
\text { the ticks }\end{array}$} & \multicolumn{4}{|c|}{ Number of PCR positive samples } \\
\hline & & & $\begin{array}{c}\text { Babe- } \\
\text { sia spp. }\end{array}$ & $\begin{array}{c}\text { Rickettsia } \\
\text { spp. }\end{array}$ & $\begin{array}{c}\text { Ehrlichia } \\
\text { canis } \\
\end{array}$ & $\begin{array}{c}\text { Hepatozoon } \\
\text { canis } \\
\end{array}$ \\
\hline \multirow{4}{*}{$\begin{array}{l}\text { Domestic } \\
\text { dogs }\end{array}$} & Rhipicephalus & Female - 17 & 0 & 0 & 8 & 0 \\
\hline & sanguineus & Male - 22 & 0 & 2 & 6 & 0 \\
\hline & Ixodes ricinus & Female -13 & 0 & 1 & 1 & 0 \\
\hline & & Male - 2 & 0 & 0 & 0 & 0 \\
\hline \multirow{2}{*}{$\begin{array}{l}\text { Red } \\
\text { foxes }\end{array}$} & Ixodes ricinus & Female -4 & 0 & 1 & 0 & 0 \\
\hline & & Male - 2 & 0 & 0 & 0 & 0 \\
\hline
\end{tabular}

collected from dogs around Sofia were from the species $R h$. sanguineus and 28\% - from the species $I$. ricinus. Our unpublished data from other studies have shown that ixodid ticks infecting house dogs in the region of Sofia were also predominantly of the $R h$. sanguineus species. These two species have been found in domestic dogs in other regions of Bulgaria and $R h$. sanguineus was also more common (Kirkova et al., 2013; Nader et al., 2018). The literature showed that $R h$. sanguineus and $I$. ricinus are common ixodid ticks parasitising on domestic dogs in Europe. They have been reported on dogs from Hungary (Földvári \& Farkas, 2005), Albania (Xhaxhiu et al., 2009; Shukullari et al., 2017), Belgium (Claerebout et al., 2013), Bosnia and Herzegovina (Krčmar et al., 2014), Germany (Rehbein et al., 2016), and Greece (Lefkaditis et al., 2016).

Only one tick species was found on red foxes in the present study - I. ricinus. It is among the common parasites of this wild carnivore in Europe. Besides Bulgaria, I. ricinus has been collected from red foxes in Hungary, Slovakia, Spain and Italy (Sréter et al., 2003; Kočišová et al., 2006; Széll et al., 2006; Martínez-Carrasco et al., 2007; Lorusso et al., 2011).

Our current study shows that $43.6 \%$ of the $R h$. sanguineus ticks were female and
$56.4 \%$ - male. The opposite was observed for I. ricinus ticks - female specimens (86.7\%) were significantly more prevalent than males $(13.3 \%)$. The tendency for $I$. ricinus collected from red foxes was similar $-66.7 \%$ of the specimens were female and $33.3 \%$ - male. The results of Nader et al. (2018) in relation to the sex of ticks collected from different hosts are similar to ours - the authors have established that I. ricinus ticks were mostly female and $R h$. sanguineus ticks were predominantly male.

The results showed that $31.7 \%$ of all investigated ticks were vectors of different pathogens. Ehrlichia sp. was identified in $79 \%$ of the infected ticks, while Rickettsia spp. -in 21\%. Ehrlichia spp. was present only in ticks collected from dogs. Fourteen of the ticks infected with Ehrlichia spp. were from the species $R h$. sanguineus $(93.3 \%)$ and only one from the species $I$. ricinus $(6.7 \%)$. This distribution of the infection in both tick species collected from dogs is not surprising because Ehrlichia canis is the aetiological agent of canine monocytic ehrlichiosis, transmitted by the brown dog tick $R h$. sanguineus, whose geographical distribution in the Neotropics overlaps with that of the pathogen (Otranto et al., 2015). Ehrlichia spp. has been previously established in $I$. 
ricinus collected from areas or dogs from Bulgaria (Christova et al., 2001; 2003; Tsachev et al., 2008; 2017; Pantchev et al., 2015). So far, no studies have reported $R h$. sanguineus as a vector of Ehrlichia sp. in our country.

In the present study Rickettsia spp. were found in four ticks - two Rh. sanguineus and two I. ricinus, one of the latter found on a fox. Rickettsia spp. have been also found in Rhipicephalus spp. and I. ricinus collected from dogs from SouthEastern Bulgaria (Nader et al., 2018). The worldwide distribution of Rickettsia spp. in dogs is discussed in a review by Otranto et al. (2015). The authors point out that no Rickettsia has been detected so far in wild carnivores in Europe. However, since some Rickettsia spp. are transmitted by ixodid species (which also feed on carnivores), the prevalence of these pathogens in wildlife is likely underestimated (Otranto et al., 2015). The detection of Rickettsia spp. in I. ricinus from a red fox in the current study supports this suggestion and confirms the potential role of foxes in the epidemiology of rickettsioses in animals and humans.

\section{ACKNOWLEDGEMENTS}

This work is connected with a co-project between the Institute of experimental morphology, pathology and anthropology with museum - Bulgarian Academy of Sciences and the Institute of Parasitology, Slovak Academy of Sciences: "Parasites in domestic and wild carnivores from Slovakia and Bulgaria in the era of global changes" (2018-2020). It is supported by the Bulgarian Ministry of Education and Science under the National Program for Research "Young Scientists and Postdoctoral Students" (Decision of the Council of Ministers $577 / 17.08 .2018)$.

\section{REFERENCES}

Casati, S., H. Sager, L. Gern \& J. Piffaretti, 2006. Presence of potentially pathogenic Babesia sp. for human in Ixodes ricinus in Switzerland. Annals of Agricultural and Environmental Medicine, 13, 65.

Christova, I., S. Panayotov, V. Levterova, E. Taseva \& T. Kantardzhiev, 2001. Detection by polymerase chain reaction of coinfection Borrelia burgdorferi s.l. and the causative agent of Human granulocyte ehrlichiosis in ticks Ixodes ricinus. Infectologia, 38, 21-24 (BG).

Christova, I., J. Van De Pol, S. Yazar, E. Velo $\&$ L. Schouls, 2003. Identification of Borrelia burgdorferi sensu lato, Anaplasma and Ehrlichia species, and spotted fever group Rickettsiae in ticks from Southeastern Europe. European Journal of Clinical Microbiology and Infectious Diseases, 22, 535-542.

Claerebout, E., B. Losson, C. Cochez, S. Casaert, A. Dalemans, A. De Cat, M. Madder, C. Saegerman, P. Heyman \& L. Lempereur, 2013. Ticks and associated pathogens collected from dogs and cats in Belgium. Parasites \& Vectors, 6, 183.

Georgieva, G. \& G. Gecheva, 2013. Fauna Bulgarica. 32. Acari, ordo Ixodida, familia Ixodidae. Bulgarian Academy of Sciences, editio academica "Professor Marin Drinov"

Estrada-Pena, A., A. Bouattour, J. L. Camicas \& A. R. Walker, 2004. Ticks of domestic animals in the Mediterranean region: A guide to identification of species. University of Zaragoza, Spain.

Földvári, G. \& R. Farkas, 2005. Ixodid tick species attaching to dogs in Hungary. Veterinary Parasitology, 129, 125-131.

Inokuma, H., M. Okuda, K. Ohno, K. Shimoda \& T. Onishi, 2002. Analysis of the $18 \mathrm{~S}$ rRNA gene sequence of a Hepatozoon detected in two Japanese dogs. Veterinary Parasitology, 106, 265-271.

Kirkova, Z., P. Iliev, M. Visser \& M. Knaus, 2013. Survey of ectoparasites of dogs 
(Canis familiaris) in Bulgaria. In: Proceedings from the $12^{\text {th }}$ International Symposium on Ectoparasites of Pets (ISEP) joint with EVPC Annual Meeting, 7-10 April 2013, Munich.

Kočišová, A., P. Lazar, V. Letková, J. Čurlík \& M. Goldová, 2006. Ectoparasitic species from red foxes (Vulpes vulpes) in East Slovakia. Veterinarski Arhiv, 76, 59-63.

Krčmar, S., J. Ferizbegović, E. Lonić \& J. Kamberović, 2014. Hard tick infestation of dogs in the Tuzla area (Bosnia and Herzegovina). Veterinarski Arhiv, 84, 177-182.

Lefkaditis, M. A., L. V. Athanasiou, A. M. Ionicã, S. E. Koukeri, A. Panorias, T. G. Eleftheriadis, \& S. Boutsini, 2016. Ectoparasite infestations of urban stray dogs in Greece and their zoonotic potential. Tropical Biomedicine, 33, 226-230.

Lorusso, V., R. P. Lia, F. Dantas-Torres, E. Mallia, S. Ravagnan, G. Capelli \& D. Otranto, 2011. Ixodid ticks of road-killed wildlife species in southern Italy: New tick-host associations and locality records. Experimental and Applied Acarology, 55, 293-300.

Martínez-Carrasco, C., M. R. De Ybáñez, J. L. Sagarminaga, M. M. Garijo, F. Moreno, I. Acosta, S. Hernández \& F. D. Alonso, 2007. Parasites of the red fox (Vulpes vulpes Linnaeus, 1758) in Murcia, southeast Spain. Revue de Médecine Vétérinaire, 158, 331-335.

Nader J., N. Król, M. Pfeffer, V. Ohlendorf, M. Marklewitz, Ch. Drosten, S. Junglen \& A. Obiegala, 2018. The diversity of tickborne bacteria and parasites in ticks collected from the Strandja Nature Park in south-eastern Bulgaria. Parasites \& Vectors, 11, 165.

Otranto, D., C. Cantacessi, M. Pfeffer, F. Dantas-Torres, E. Brianti, P. Deplazes, C. Genchi, V. Guberti \& G. Capelli, 2015. The role of wild canids and felids in spreading parasites to dogs and cats in $\mathrm{Eu}-$ rope: Part I: Protozoa and tick-borne agents. Veterinary Parasitology, 213, 12-23.
Pancholi, P., C. Kolbert, P. Mitchell, K. Reed, J. Dumler, J. Bakken, S. Telford \& D. Persing, 1995. Ixodes dammini as a potential vector of human granulocytic ehrlichiosis. Journal of Infectious Diseases, 172, 1007-1012.

Pantchev, N., M. Schnyder, M. Vrhovec, R. Schaper \& I. Tsachev, 2015. Current surveys of the seroprevalence of Borrelia burgdorferi, Ehrlichia canis, Anaplasma phagocytophilum, Leishmania infantum, Babesia canis, Angiostrongylus vasorum and Dirofilaria immitis in dogs in Bulgaria. Parasitology Research, 114, 117-130.

Parola, P. \& D. Raoult, 2001. Tick-borne bacterial diseases emerging in Europe. Clinical Microbiology and Infection, 7, 80-83.

Perez de Leon, A. A., E. Vannier, C. Almazan \& P. J. Krause, 2013. Tick-borne protozoa. In: Biology of Ticks, $6^{\text {th }}$ edn, ed D. E. Sonenshine \& R. M. Roe. OUP USA.

Pfeffer, M. \& G. Dobler, 2011. Tick-borne encephalitis virus in dogs - is this an issue? Parasites \& Vectors, 4, 59.

Rehbein, S., K. H. Kaulfuss, M. Visser, M. F. Sommer, F. Grimm, \& C. Silaghi, 2016. Parasites of sheep herding dogs in central Germany. Berliner Und Munchener Tierarztliche Wochenschrift, 129, 56-64.

Sekeyová, Z., V. Roux \& D. Raoult, 2001. Phylogeny of Rickettsia spp. inferred by comparing sequences of 'gene D', which encodes an intracytoplasmic protein. International Journal of Systematic and Evolutionary Microbiology, 51, 1353-1360.

Shukullari, E., D. Rapti, M. Visser, K. Pfister $\&$ S. Rehbein, 2017. Parasites and vectorborne diseases in client-owned dogs in Albania: Infestation with arthropod ectoparasites. Parasitology Research, 116, 399-407.

Sréter, T., Z. Széll \& I. Varga, 2003. Ectoparasite infestations of red foxes (Vulpes vulpes) in Hungary. Veterinary Parasitology, 115, 349-354.

Stojek, N. M. \& J. Dutkiewicz, 2004. Studies on the occurrence of Gram-negative bacteria in ticks: Ixodes ricinus as a potencial 
vector of Pasteurella. Annals of Agricultural and Environmental Medicine, 11, 319-322.

Széll, Z., Z. Sréter-Lancz, K. Márialigeti \& T. Sréter, 2006. Temporal distribution of Ixodes ricinus, Dermacentor reticulatus and Haemaphysalis concinna in Hungary. Veterinary Parasitology, 141, 377-379.

Tsachev, I., A. Ivanov, I. Dinev, G. Simeonova \& D. Kanakov, 2008.Clinical Ehrlichia canis and Hepatozoon canis co-infection in a dog in Bulgaria. Revue de Médecine Vétérinaire, 159, 68-73.

Tsachev, I., E. Padogiannakis, V. Kontos, I. Zarkov, V. Petrov \& V. Pelagic, 2017. Seroprevalence of Ehrlichia canis infection among privately-owned dogs in northern Bulgaria. Journal of the Hellenic Veterinary Medical Society, 57, 212-216.

Xhaxhiu, D., I. Kusi, D. Rapti, M. Visser, M. Knaus, T. Lindner \& S. Rehbein, 2009.
Ectoparasites of dogs and cats in Albania. Parasitology Research, 105, 1577-1587.

Paper received 21.11.2019; accepted for publication 20.01.2020

\section{Correspondence:}

Assoc. Prof. Mariana Panayotova-Pencheva Institute of Experimental Morphology,

Pathology and Anthropology with Museum Bulgarian Academy of Sciences, Acad. G. Bonchev St., Block 25, 1113 Sofia, Bulgaria e-mail: marianasp@abv.bg 